\title{
Interactive comment on "The new BELUGA setup for collocated turbulence and radiation measurements using a tethered balloon: First applications in the cloudy Arctic boundary layer" by Ulrike Egerer et al.
}

\section{Anonymous Referee \#2}

Received and published: 31 May 2019

This paper documents the setup and capabilities of the new tethered balloon "BELUGA" and presents results from flights that measured a single layer cloud, a multi-layer cloud, and clear-sky conditions during the PASCAL campaign. The setup currently includes instruments that measure winds, temperature, relative humidity, turbulent fluxes, and broadband radiative fluxes. The balloon can fly up to $1.5 \mathrm{~km}$. Instruments are currently being developed to measure aerosols and cloud microphysics.

This paper is carefully written and provides a detailed description of the new modular tethered balloon system. This is a very important development that will provide new 
insights into Arctic boundary layers and will provide the measurements needed to validate and improve turbulent and microphysical model parameterizations. I believe this paper is suitable for publication after minor revisions.

Comments:

1) Page 1, line 5-6: "Collocated data acquisition allows for estimates of the driving parameters in the energy balance at various heights."

comment

2) Page 2, line 11: "The majority of Arctic clouds are located with the ABL."

3) Page 5, Figure 2 caption: "HW" should read "HP".

4) Page 6, line 11: "The data streams are synchronized by an analog..."

5) Page 18, line 6: “. . are slightly separated in altitude...”

6) Page 19, line 2: “. . north of Svalbard around 81.8N during 5-14 June 2017."

7) Page 20, Figure 10 caption: "The cloud extent is indicated by gray shading."

8) Page 21, line 3-5: Given the uncertainty in the estimates it is not clear that a nearsurface mixed layer can be distinguished from the main cloud-driven mixed layer.

9) Page 21, line 9: "Contrary to Eq. 9..."

10) Page 24, line 12: “...they provide near-vertical profiles of collocated measurements. These vertical profiles enable the study of ..."

11) Page 25, line 4: “...instruments allows the pursuit of specific..."

Interactive comment on Atmos. Meas. Tech. Discuss., doi:10.5194/amt-2019-80, 2019. 